\title{
PESQUISA EM ENFERMAGEM PSIQUIÁTRICA: CONCEPÇÕES E EXPECTATIVAS DE ENFERMEIROS QUE ATUAM EM INSTITUIÇÕES PSIQUIÁTRICAS
}

\author{
Dora Sadigursky** \\ Iêda Helena Hurst* \\ José Lucimar Tavares** \\ Josicelia Dumêt Fernandes*** \\ Maria Rita de Oliveira Oliveira*
}

SADIGURSKY, D.; HURST, I.H.; TAVARES, J.L.; FERNANDES, J.D.; OLIVEIRA, M.R.de O. Pesquisa em enfermagem psiquiátrica: concepções e expectativas de enfermeiros que atuam em instituições psiquiátricas. Rev. latino-am. enfermagem, Ribeirão Preto, v. 6, n. 5, p. 89-98, dezembro 1998.

Esta investigação tem como objeto de estudo as concepções e expectativas de enfermeiros que atuam em instituições psiquiátricas, em relação às pesquisas desenvolvidas nessa área. Tem como objetivo, identificar essas concepções e expectativas, possibilitando traçar um perfil sobre o processo de divulgação e utilização dessas pesquisas na atenção e administração da assistência de Enfermagem Psiquiátrica. Foi desenvolvida junto a enfermeiros que trabalham em instituições psiquiátricas da cidade de Salvador, durante o mês de março do corrente ano. Foram entrevistados 25 enfermeiros que se encontravam em serviço no período previsto para a realização da coleta de dados, os quais emitiram suas opiniões concernentes ao tema em apreço, através de um roteiro de entrevista semi-estruturada. Os resultados, qualitativamente analisados, apoiaram-se nos pressupostos teórico-metodológicos das Representações Sociais, permitindo concluir-se que a maioria dos enfermeiros entrevistados referiu não ter acesso às pesquisas especificas da área, bem como demonstrou dificuldade em estabelecer relação e influência dessas pesquisas nos seus serviços, muito embora admitissem sua importância para o desenvolvimento pessoal e profissional, o que, por certo repercutiria, sobremaneira, na assistência prestada pelo enfermeiro.

UNITERMOS: pesquisa, pesquisa em enfermagem, enfermagem psiquiátrica

\section{INTRODUZINDO O TEMA}

No Brasil, a pesquisa em enfermagem vem evoluindo de forma lenta e gradual. Apesar de Florence Nightingale, no século XIX, já ter utilizado princípios científicos no planejamento da assistência de enfermagem, a pesquisa, em nosso meio, não foi incorporada à nossa prática, de imediato.

FERNANDES (1985), analisando a situação da pesquisa numa unidade de ensino de enfermagem, evidenciou que somente a partir dos anos 60 , face às solicitações da expansão das forças produtivas e de conhecimento de relevância social, a enfermagem brasileira sente a necessidade de ampliar seus conhecimentos e produzir novos saberes. Um dos caminhos mais adequados para privilegiar essa necessidade foi, evidentemente, a pesquisa. Assim é que, na década de 60 , observa-se a realização das primeiras pesquisas de relevância na enfermagem. Em 1964, o tema "Enfermagem e Pesquisa" constou, pela primeira vez, da temática de um Congresso Brasileiro de Enfermagem, demonstrando a preocupação dos enfermeiros em destacar a pesquisa como forma de produzir novos conhecimentos.

A partir daí, as mudanças decorrentes do desenvolvimento científico têm impulsionado os enfermeiros para a produção de novos conhecimentos e para a identificação da forma como essa produção está sendo utilizada pela categoria. Esse desenvolvimento, por sua vez, foi, fundamentalmente, impulsionado pelo crescimento da investigação científica acionada pelos primeiros cursos de pós-graduação em enfermagem, iniciados, no país, na década de 70. Estes cursos, não só favoreceram mas, também, exigiram o aperfeiçoamento dos profissionais na atividade de pesquisa voltada, sobretudo, para a elaboração de monografias, dissertações

\footnotetext{
* Mestras em Enfermagem - Professoras de Enfermagem Psiquiátrica da EEUFBA

** Doutorandos em Enfermagem - Professores de Enfermagem Psiquiátrica da EEUFBA

*** Doutora em Enfermagem - Professora Visitante da EEUFBA
} 
e teses que buscavam atender a creditação dos mesmos no que diz respeito a aquisição de títulos acadêmicos.

Sob essa ótica, as pesquisas produzidas nesses cursos, nem sempre foram possuidoras de aplicabilidade imediata para atender os aspectos prioritários da prática nos serviços de saúde. Reconhecendo essa realidade, os enfermeiros, a partir dos anos 80 , começaram a dirigir sua atenção para a aplicabilidade dos resultados das pesquisas objetivando a melhoria da qualidade da prática de enfermagem. Nesse direcionamento, o IV Seminário Nacional de Pesquisa em Enfermagem, em 1985, já demonstrava a preocupação dos enfermeiros com a utilidade social de suas pesquisas.

A partir daí, verificou-se, na enfermagem, um aumento da produção científica. Este incremento deveria implicar na constituição de um lastro para a melhoria e transformação da prática. Entretanto, não é isto o que se vem observando, no cotidiano da enfermagem. As pesquisas não vêm se constituindo numa atividade sistemática dos enfermeiros nas instituições prestadoras de serviços; verifica-se, também, que estas instituições não têm adotado uma postura institucional de aderência às atividades de pesquisa, ficando, as mesmas, restritas ao âmbito das universidades.

$\mathrm{Na}$ área de Enfermagem Psiquiátrica, ARANTES (1985) destaca que as pesquisas tiveram sua origem após a II Guerra Mundial, nos Estados Unidos, quando a legislação americana destinou fundos para o aprimoramento de pessoal que trabalhava na área de Saúde Mental. No Brasil, entretanto, mesmo nos dias de hoje, não se observa uma política voltada para a formação e aprimoramento de pessoal que trabalha nessa área, o que tende a dificultar a produção de pesquisas específicas. A este respeito, STEFANELLI et al. (1987), estudando as pesquisas em Enfermagem Psiquiátrica, em nosso país, não encontraram nenhuma referência de resultados de pesquisas que tivessem sido incorporados às atividades práticas.

Diante destas considerações, os autores do presente estudo verificaram, na sua área de atuação, isto é, na prática da Enfermagem Psiquiátrica, que os enfermeiros, ocupados na reprodução dos conhecimentos já existentes, acomodam-se às rotinas de trabalho das instituições, não chegando a realizar atividades de pesquisa e/ou utilizar novos conhecimentos em busca de soluções para os graves problemas existentes na assistência ao doente mental.

Partindo desta constatação e preocupados, não somente com a qualidade da assistência prestada à clientela nos serviços psiquiátricos, mas também com a escassa produção científica na área específica, os autores deste trabalho, enquanto docentes de Enfermagem Psiquiátrica e Saúde Mental, resolveram realizar a presente investigação que busca conhecer as concepções e expectativas dos enfermeiros, que atuam em instituições psiquiátricas, sobre as pesquisas desenvolvidas nessa área, procurando identificar a origem, não só da escassez de pesquisas realizadas por estes profissionais, como também da sub-utilização de novos conhecimentos produzidos na área de Enfermagem Psiquiátrica. Nesta busca, os autores procuraram considerar o fenômeno estudado em toda sua plenitude e significado, verificando a dimensão social e psicológica das concepções e expectativas dos enfermeiros, através de suas falas. Os autores adotaram como eixo da sua análise a teoria das Representações Sociais de MOSCOVICI (1978) e partem do pressuposto que o ambiente de trabalho e o espaço ocupado pelos enfermeiros formam o contexto no qual se desenvolvem as suas concepções e expectativas acerca das pesquisas da área. Este pressuposto, por sua vez, prende-se à constatação de BLEGER (1993), de que a conduta de um ser humano ou de um grupo se dá sempre num contexto de vínculos e relações humanas interatuantes em cada momento.

A teoria das Representações Sociais elabora-se a partir das experiências vividas, onde o indivíduo interpreta e elabora o real, construindo realidades sociais. Através de uma ótica psicossocial, esta teoria possibilita maior compreensão e reconhecimento do ser humano em sua complexidade. Ela se constitui, portanto, em importante instrumento de aproximação e compreensão da realidade vivenciada pelos enfermeiros em relação à pesquisa nos serviços de saúde e, mais especificamente, nos serviços psiquiátricos, pois fornece os elementos técnicometodológicos capazes de favorecer uma compreensão da realidade desses profissionais.

As Representações Sociais (RS) dos enfermeiros, em relação à pesquisa, são, aqui, entendidas como uma forma de conhecimento socialmente elaborado e partilhado que, originando-se nas relações interpessoais do universo de cada enfermeiro, influenciam na conduta dos mesmos para com a pesquisa e contribuem para a construção de uma realidade social na enfermagem.

Os achados, do presente estudo, resultarão num chamamento, que deverá conduzir os enfermeiros docentes e de serviços para uma reflexão crítica de suas práticas, especialmente no que concerne à produção, divulgação e utilização de novos conhecimentos na área de enfermagem psiquiátrica.

\section{COMPREENDENDO AS REPRESENTAÇÕES SOCIAIS}

A teoria das Representações Sociais elabora-se a partir das experiências vividas onde o indivíduo interpreta e elabora o real, construindo realidades sociais. 
Para MOSCOVICI (1978) as Representações Sociais se constituem num "sistema de valores, de noções e de práticas, tendo uma dupla tendência: antes de tudo instaurar uma ordem que permita aos indivíduos a possibilidade de se orientar no meio ambiente social e de o dominar. Em seguida, de assegurar a comunicação entre os membros de uma comunidade propondo-lhes um código para as suas trocas e um código para nomear e classificar de maneira unívoca as partes de seu mundo, de sua história individual ou coletiva". Elas se constituem numa modalidade de conhecimento particular que tem por função a elaboração de comportamentos e a comunicação entre indivíduos; originam-se nas relações interpessoais e, uma vez constituídas, influenciam nas condutas dos indivíduos para com o objeto social em questão.

NÓBREGA (1990), discorrendo sobre o processo de formação das Representações Sociais elaboradas por Sérge Moscovici, refere que este processo se dá através da objetivação e da ancoragem, os quais articulam o ato cognitivo com o contexto social de onde emergem as Representações Sociais.

Por objetivação, o autor entende como o mecanismo que possibilita a corporificação daquilo que é abstrato; é o processo básico das concepções sociais compartilhadas; se constitui em três fases distintas e interrelacionadas, a saber:

- Construção seletiva - que compreende a apropriação, pelas pessoa, de certo corpus teórico-científico, comumente divulgado pelos meios de comunicação de massa, constituindo-se no senso comum; esta seleção baseia-se em padrões naturais que, em geral são estabelecidos pelas desigualdades sociais e conseqüente dificuldade de acesso às informações, bem como pelas necessidades, valores e crenças de cada grupo social.

- Esquematização estruturante - é determinada pela natureza do objeto (fenômeno) e sua relação com o indivíduo, constituindo-se, assim, no núcleo das Representações, encerrando as funções geradoras e organizadoras do processo.

- Naturalização - consiste no reflexo do abstrato no real, materializando-se e determinando o espaço das concepções. Assim, naturalizam-se as concepções, adquirindo um status de realidade, isto é, uma existência concreta.

Moscovici apud NÓBREGA (1990) aponta a ancoragem como organizada sob três aspectos importantes:

- Atribuição do sentido - ocorre quando se procura apoiar o pensamento novo no pensamento já constituído, a fim de adequar os novos conhecimentos aos já existentes.

- Instrumentalização do saber - fornece a funcionalidade da Representação, permitindo aos indivíduos a compreensão da realidade. A relação que se verifica entre o indivíduo e o meio ambiente é formada pela nova interpretação, transformando-a em um saber utilizável.

- Enraizamento no sistema de pensamento - referese ao movimento de "incorporação social da novidade".

De acordo com essas considerações, entendese que, nesse processo, atribui-se sentido ao fenômeno, em seguida instrumentaliza-se o saber sobre este fenômeno e, por fim, fixa-se a nova concepção no sentido do pensamento. A ancoragem se traduz, portanto, no modo pelo qual as novas informações são agrupadas e modificadas em um conjunto de conhecimentos socialmente estabelecidos, bem como no conjunto das significações disponíveis que permitem interpretar o real; ela apresenta uma relação dialética com a objetivação garantindo a apreensão do novo, compreensão da realidade e direcionamento dos comportamentos.

Diante desse quadro, entendemos que a R.S situa-se no ponto de interseção entre o psicológico e o social. Assim, o processo de interação social, no que concerne à produção, difusão e utilização de conhecimentos científicos, dos enfermeiros, permite captar aspectos específicos da realidade desses profissionais.

Sendo a enfermagem uma profissão historicamente estabelecida pela forma como a sociedade se organiza, tem como determinantes de sua prática os princípios e valores que norteiam as atividades econômicas, políticas e culturais dessa sociedade. As Representações Sociais que os enfermeiros expressam foram, ao longo dos anos, sendo consolidadas, tanto internamente, pelo conjunto de valores sociais que orientam esses profissionais, como externamente, pela atuação desses indivíduos na comunidade que, por sua vez, também, construíram, através dos tempos, suas representações em relação a essa profissão. As RS dos enfermeiros têm, no seu contexto, uma historicidade e constroem esquemas de concepções e expectativas acerca das pesquisas, ou seja, estas concepções e expectativas são próprias da história interpessoal e profissional de cada enfermeiro. Destarte, ao serem estudadas as RS das concepções e expectativas dos enfermeiros em relação às pesquisas na área de EP, devem ser consideradas não só as estruturas, as organizações cognitivas e suas formas de interação, mas também o conteúdo e as origens sociais da mesma.

\section{O CAMINHO METODOLÓGICO}

Este trabalho se constitui num estudo descritivo exploratório, onde são priorizadas as falas dos enfermeiros, por entender-se que as mesmas podem retratar as 
experiências do cotidiano desses profissionais e por se constituir numa forma de Representação. Apoia-se nos pressupostos teórico-metodológicos das RS e adota, como técnica de análise, a Análise Temática, pois os mesmos mostraram-se suficientes para o alcance dos objetivos propostos.

A Análise Temática como uma modalidade de Análise de Conteúdo, apoia-se numa concepção da comunicação como processo e não como algo dado, estático, além de desviar-se das estruturas e dos elementos formais (MINAYO, 1994). Esta técnica de análise direcionou-se para as falas dos enfermeiros, buscando os significados manifestos e latentes expressos nas suas concepções e expectativas, acerca das pesquisas realizadas na área de Enfermagem Psiquiátrica.

Foram entrevistados 25 (vinte cinco) enfermeiros atuantes na área psiquiátrica de 9 (nove) hospitais de uma capital do nordeste, durante o mês de março de 1997.

O instrumento utilizado foi a entrevista semiestruturada, por permitir maior flexibilidade para possíveis intervenções e por possibilitar uma investigação mais ampla sobre o entrevistado (BLEGER, 1993). O roteiro da entrevista constou de duas partes distintas. Na primeira, a caracterização da amostra, procurou-se verificar: tempo de formado, tempo de serviço em enfermagem e tempo de serviço em psiquiatria, cargo que ocupa, titulação, produção e/ou divulgação de algum trabalho científico, assinatura de algum periódico. A segunda parte constou de 3 (três) questões norteadoras e direcionadas para o tema em pauta: Qual a sua concepção sobre as pesquisas em enfermagem psiquiátrica? Quais suas expectativas em relação a elas? Como essas pesquisas influenciam no seu serviço?

As entrevistas foram gravadas após consentimento dos sujeitos do estudo e lhes dada a garantia do anonimato, bem como da reprodução fiel dos seus depoimentos.

Apesar dos autores estarem conscientes de que o real não se apresenta claramente ao pesquisador, por mais familiaridade que este tenha com o fenômeno estudado, procurou-se, nesta investigação, ir além da aparência (ir à essência), buscando identificar as percepções e expectativas dos enfermeiros, cuja presença ou freqüência, pudessem ter um significado para o objeto de estudo. Acompanhando PERRUSI (1995), os autores, ao interpretarem as falas, procuraram "caminhar" do conteúdo manifesto para o conteúdo latente, o que implicou em ultrapassar aquilo que é externado e buscar os significados ocultos, pois uma interpretação jamais esgota o material de uma entrevista, que pode ser superada por outra mais complexa e profunda, até porque cada interpretação servirá de base para uma outra.

A análise das entrevistas foi submetida a tratamento como uma totalidade e foi realizada através dos seguintes passos:

- Transcrição de cada entrevista, constituindo um texto. - Leitura exaustiva dos textos transcritos, possibilitando o acompanhamento e atenção para alguns trechos mais significativos das experiências dos sujeitos e de suas RS sobre a produção do conhecimento e sua aplicabilidade nos serviços.

- Seleção dos dados mais relevantes apresentados nas falas, objetivando o alcance da compreensão do texto. Foi feito um recorte dos textos em unidades de significação que se constituíram em frases sobre o tema.

\section{ANALISANDO, INTERPRETANDO E DISCUTINDO OS RESULTADOS}

Na presente análise, foram entrevistados 25 (vinte cinco) enfermeiros, dos quais 09 (36\%) tinham até 5 (cinco) anos de formados, 21 (84\%) possuíam apenas curso de graduação; a maioria, isto é, 14 (56\%) tinham até 05 (cinco) anos de serviço na área psiquiátrica e 19 (76\%) eram enfermeiros ligados diretamente a assistência psiquiátrica; 20 (80\%) não realizaram nenhum tipo de produção científica e 24 (96\%) não tinham assinatura de nenhum periódico relativo à enfermagem.

Ao analisar as falas, os autores deste estudo consideraram as mesmas como um processo de elaboração, dinâmico, composto de contradições e imperfeições e não como um processo acabado; através delas foi possível captar as concepções e expectativas que os enfermeiros desenvolvem através de seus contextos e significados. Elas foram apreendidas como entrelaçadas às experiências pessoais de cada sujeito nas suas vivências pessoal e profissional, o que significa a construção das características próprias de cada um. O significado das falas dos enfermeiros estão, portanto, no imaginário social e pessoal dos mesmos e tem como resultado as atuações no mundo externo desses profissionais, isto é, na maneira como eles concebem e se comportam em relação às pesquisas.

A partir desse entendimento, procurou-se explicar as relações estabelecidas entre o enfermeiro e a pesquisa, ou sejam, as fontes de elaborações psíquicas à realidade e o modo de agir sobre esta realidade.

\section{Concebendo a pesquisa:}

Ao serem questionados acerca da "sua concepção sobre as pesquisas em Enfermagem Psiquiátrica", 09 (36\%) dos enfermeiros conceberam as mesmas como a busca de novas formas de atuação, 
através de novos conhecimentos norteadores da prática de Enfermagem Psiquiátrica; 07 (28\%) desses profissionais conceberam essas pesquisas como importantes e necessárias, embora não as realizem, nem tampouco procuram conhecer as já existentes na área; $09(36 \%)$ registraram não ter idéia do que seja pesquisa e nem sabem como fazê-las.

Apesar da maioria dos enfermeiros ter demonstrado desconhecimento acerca do que seja uma pesquisa, $09(36 \%)$ desses profissionais revelaram familiaridade com a mesma, conforme explicitam algumas falas, a seguir transcritas:

"Eu acredito que pesquisar é repensar, é buscar respostas e novas formas de atuação, tendo como base a pesquisa científica, que deve ser usada como um suporte para a prática".

"Pesquisa é um forte instrumento norteador de todo e qualquer trabalho".

"É um instrumento de mudança pela produção de novos conhecimentos e de melhoria pela aplicação desses novos conhecimentos"

Observa-se que os sujeitos destas falas demonstraram compreensão da realidade e incorporaram essa realidade no seu pensamento. Eles revelaram, explicitamente, um conceito de pesquisa, provavelmente apreendido durante a formação profissional, o que pode significar uma concepção já introjetada e reelaborada a partir de sua própria vivência e experiência profissional, constituindo-se, de fato, uma representação. Sobre isto, VALA (1993) nos diz que Representação é sempre a expressão de um sujeito e não um mero reflexo de um objeto, mas, sim, um produto proveniente do confronto entre a atividade mental e as relações complexas que são mantidas com o objeto, resultando em modelização e simbolização.

Vale salientar que esses profissionais, sujeitos desta investigação, embora reconheçam a importância da pesquisa no trabalho da enfermagem, não a realizam, usando, para isto, os mesmos argumentos daqueles que revelaram desconhecer o processo em questão; esses sujeitos, agrupados, somam 16 (64\%) dos depoimentos que apontam a pouca familiaridade com o conceito de pesquisa e as etapas necessárias para a realização das mesmas.

Resultados semelhantes a estes foram encontrados por LOPES (1989), quando constatou que os enfermeiros viam de forma positiva a aplicação dos resultados de pesquisas, pelo fato de estarem em contato direto com o paciente. No entanto, este mesmo estudo evidenciou, também, que os enfermeiros de serviços acreditavam ser o enfermeiro docente o mais capacitado para realizar pesquisas, por acreditarem que esta é uma tarefa própria da academia. Nesta mesma linha de pensamento, CASTRO et al. (1985), já encontraram indicativos de que os enfermeiros de serviços não se reconhecem no papel de produtores, assim como de consumidores das pesquisas produzidas por se considerarem à parte dos mundo dos pesquisadores.

Estas são concepções socialmente estabelecidas e que devem ser questionadas uma vez que a formação recebida nos cursos de graduação foi a mesma, tanto para os enfermeiros que hoje estão nos serviços quanto para os que estão na docência. A despeito disto, as pesquisas estão sendo desenvolvidas, fundamentalmente, no meio universitário e não nos serviços, principalmente em virtude das exigências de produção científica dos cursos de pós-graduação, o que não ocorre nas instituições prestadoras de serviços de saúde. Estas, na sua grande maioria, não estimulam os enfermeiros para renovação do conhecimento através de novos achados advindos da pesquisa. Esta realidade se constitui num fator que interfere na construção da concepção ou representações sociais sobre o processo de produção, divulgação e utilização de novos conhecimentos na enfermagem psiquiátrica, uma vez que essas representações se constituem através da interação entre os sujeitos e os elementos contextuais que influenciam na apreensão e reelaboração do novo.

Dos enfermeiros entrevistados, 16 (64\%) disseram claramente que não sabiam conceituar pesquisa ou não forneceram uma resposta adequada à questão, conforme se pode observar em alguns dos depoimentos, ilustrados a seguir:

"É o seguinte, pra ser sincera mesmo, eu não tenho nenhuma experiência no assunto 'pesquisa'. Eu não tenho nenhuma idéia formada em relação a isso. Fica difícil responder".

"Estou completamente por fora desta parte de 'pesquisa'. Não sei nada sobre 'pesquisa' e não estou, no momento, interessada em saber. Não sei qual a minha concepção e também nunca me preocupei em saber".

"Não sei como responder, não tenho nem idéia”.

"Eu tenho pouco tempo de psiquiatria e não tenho melhores informações. Pra mim, eu acho que é assim um trabalho que eu estou precisando muito, como enfermeira, sabe? "Eu acho interessante pelo seguinte...porque na psiquiatria as pessoas não dão muito valor, é uma área muito esquecida. Seria interessante fazer um estudo para divulgar mais a psiquiatria".

"Eu acho até que é válido, pelo menos para 
renovar os pacientes que a gente tem; é uma coisa tão empírica atualmente que o paciente vai e volta. Eu acho que é válido se pesquisar para ver como está sendo feito o tratamento aí fora, para ver se a gente melhora a assistência".

Os enfermeiros, sujeitos desta pesquisa, se consideram sem preparo e sem estímulo para a realização de pesquisas, apontando como justificativas, sobretudo, a ausência de conhecimentos sobre a metodologia científica, falta de incentivo institucional e sobrecarga de trabalho por possuírem mais de um emprego. Assim, os enfermeiros, frente à sua realidade, interpretam-na, procurando apoiar seu pensamento na percepção dessa realidade, o que interfere na sua aproximação com o processo de produção, divulgação e utilização de conhecimento, na área. Neste sentido, corroboramos as idéias de NÓBREGA (1990), quando diz que as Representações circulam nos discursos e se materializam nas condutas; se efetivam nas interações realizadas entre os sujeitos e o objeto, mediadas pelo sistema de interpretação do indivíduo ou do grupo.

Destaca-se, ainda, algumas falas que podem ilustrar as dificuldades com as quais se deparam os enfermeiros na aproximação com o fenômeno 'pesquisa'.

"A gente faz faculdade, tem a matéria, mas ensina muito pouco; a gente sai mesmo sem saber, sem ter um conceito do que é pesquisa e sem saber fazer pesquisa para usar na vida profissional”.

"A gente tem uma carga horária né... a gente só tem tempo pra fazer as atividades da gente aqui dentro; não tem um tempo extra, sabe, um estímulo pra que a gente possa fazer uma pesquisa”.

"Já me senti muito estimulada, mas faltou conhecimento, habilidade tempo e incentivo do hospital".

"Não temos nenhum estímulo do hospital...,fica tudo na mesma coisa. $O$ Estado...você sabe como é, não é? Às vezes a gente vê muita coisa que precisa ser estudado, mas não tem nenhum incentivo nem estímulo, até dos próprios colegas do serviço".

"Aqui não se dá estímulo para nada. Às vezes a gente vê as coisas e não se pode nem falar, quanto mais fazer pesquisa. E depois não tem nem tempo, tem que sair daqui correndo para outro serviço".

"Pra ser sincera a gente vê muita coisa aqui que dava para fazer pesquisas e muito boas, mas não se tem nenhum estímulo. Fica só nos controles, na escala, com o doente

e o tempo não dá”.

$\mathrm{O}$ que se apreende dessas falas é que, apesar das adversidades inerentes ao processo de trabalho da enfermagem, os enfermeiros detêm um saber intrínseco à sua categoria e têm uma determinada consciência da realidade. A este respeito, ALVES (1995) aponta que não há ação sem saber e a enfermagem, como prática social, não apenas aplica/reproduz conhecimento, como também produz conhecimento no cotidiano do seu trabalho, através do ato de 'improvisar', pois as dificuldades geram possibilidades de produzir conhecimento.

LOPES (1989); CASTRO et al. (1985) e BARNET (1981) constataram que as dificuldades dos enfermeiros no trabalho estão ligadas, também, a falta de hábito de leitura, dificuldade de acesso a livros, ausência de local apropriado para estudos, falta de intercâmbio e de informações, falta de tempo, sobrecarga de trabalho e ocupação com outras atividades; atribuem, no entanto, como maior dificuldade, a falta de incentivo institucional, isto é, a falta de uma política institucional que direcione o processo de pesquisa nos serviços. Estas dificuldades foram identificadas, também, nos achados da presente investigação, evidenciando a persistência das mesmas, ainda em nossos dias.

As dificuldades acima relatadas pelos enfermeiros entrevistados trazem a marca dos aspectos subjetivos (políticos e ideológicos) que gerenciam o processo de trabalho e são revestidos de importância fundamental na determinação dos limites e possibilidades de aproximação, desses profissionais, com o processo de produção, divulgação e utilização do conhecimento.

\section{Tendo expectativas em relação às pesquisas:}

Dentre os sujeitos deste estudo, 21 (84\%) esperam que as pesquisas tenham aplicabilidade na prática da assistência de enfermagem psiquiátrica e que sejam divulgadas com vistas à melhoria dessa assistência. Por outro lado, 04 (16\%) deles não têm nenhuma expectativa porque não acreditam que as pesquisas possam trazer alguma mudança para a prática.

A maioria (84\% ou 21 enfermeiros) revelou, portanto, que espera que as pesquisas na área continuem a ser realizadas, que sejam divulgadas mais amplamente e que tenham utilidade prática de modo a implementar a melhoria da qualidade da assistência prestada aos pacientes conforme alguns dos depoimentos, abaixo transcritos:

"Espero que ajude a melhorar a nossa prática e que sirva para melhorar a qualidade da assistência ao paciente, família e comunidade”. 
"Espero que contribuam para melhorar o desempenho profissional pela descoberta de novas formas de atuação junto ao paciente".

"Espero que leve o conhecimento novo para a prática, influenciando-a, modificando-a e melhorando-a".

"Espero que venha ajudar a melhorar a assistência. A gente fica perdido; a gente quer melhorar o conhecimento $e$ a assistência ao doente".

"Seria importante que a gente tivesse acesso a elas, mas poucas são divulgadas. Deveria ter um meio de divulgação, pois a gente fica no serviço, se envolve no trabalho e não tem conhecimento do que tem de novo".

Das falas anteriormente ilustradas, apreende-se que os entrevistados reconhecem a importância das pesquisas, e que têm expectativas quanto à sua aplicabilidade como caminho alternativo para a melhoria da sua prática profissional.

Os enfermeiros ( $16 \%$ ou 04 deles) que revelaram não possuir nenhuma expectativa em relação às pesquisas por não acreditarem que as mesmas possam trazer alguma mudança para a prática ou atender às necessidades no campo profissional, têm alguns dos seus depoimentos ilustrados a seguir:

'Não tenho nenhuma expectativa. Estou muito céptica, não vejo nada melhorar. A verdade é que não espero nada das pesquisas em enfermagem psiquiátrica; não acredito que elas possam mudar nada".

"Não sei e nem tenho idéia...."

"Eu não sei é nada!... Essa Reforma

Psiquiátrica que não chega....!"

Apreende-se destas falas que $04(16 \%)$ dos enfermeiros, sujeitos desta pesquisa, assumem uma atitude de 'consentimento', de acomodação às rotinas de trabalho, sem possibilitar a percepção do "novo"; suas concepções mais antigas, fortemente arraigadas, parecem não permitir o caráter criador, dificultando a associação de outros saberes a essa realidade, já fortemente estabelecida.

Esses enfermeiros parecem consentir na construção dessa realidade e a produção desse consentimento, seja no trabalho ou no comportamento desses profissionais, varia de acordo com a visão de mundo de cada um, das variações de consciência que vêm de fora do trabalho, das relações externas e do tipo de personalidade, revelando a forma de cada um ver o mundo de acordo com suas experiências de vida. Vale salientar que as expectativas desses enfermeiros estão condicionadas, portanto, não só pelas questões relativas à sua prática profissional e pela sua posição no processo de trabalho, mas também por suas questões pessoais, por pertencer a determinado grupo social, firmando a concepção de que a inclusão de indivíduos de diferentes grupos sociais dentro da sociedade, confere-lhes, também, formas distintas de agir, pensar e se expressar sobre a realidade que vivenciam.

Vale destacar que o conteúdo das falas estudadas mostra que os seus sujeitos encontram-se descrentes em relação às pesquisas da área por não, perceberem a aplicabilidade das mesmas. Estas falas apontam para a necessidade de serem implementadas pesquisas que possam contribuir, concretamente, para a transformação da realidade aqui apresentada. A este respeito, WESTRUPP et al. (1994) destacam a trivialidade das informações contidas em algumas pesquisas de enfermagem e apontam para a necessidade de ampla divulgação daquelas que contenham valor informativo e que contribuam para a transformação da prática de enfermagem.

O processo de constituição das representações sociais, aqui estudado, indica que, para o conhecimento "estranho" se tornar "familiarizado" e, consequentemente, utilizável, torna-se necessário uma determinação do indivíduo ou grupo, evitando que ocorra apenas o predomínio dos conhecimentos antigos, já solidificados, além de buscar o desenvolvimento do aspecto criativo que deverá permitir, não só a absorção do "novo", como também sua reelaboração.

\section{Percebendo a influência das pesquisas nos serviços:}

Os enfermeiros, isto é, 09 (36\%) perceberam que as pesquisas em enfermagem psiquiátrica influenciam nos serviços, aumentando o conhecimento dos profissionais e levando-os a mudança de atitudes na prática. Em contrapartida, 16 (64\%) dos enfermeiros externaram não saber como essas pesquisas podem influenciar nos serviços porque não acreditam na relevância das mesmas.

Estas respostas revelam que a maioria dos profissionais tem uma concepção sobre pesquisa que os leva a desconhecer as influências que ela pode trazer para o serviço. O não acesso às pesquisas, a descrença de que possam influenciar sua prática e de que não são relevantes para a categoria, destacam-se em algumas falas, ilustradas a seguir:

"Acredito que as pesquisas possam e devam influenciar nos serviços, mas no caso das pesquisas em enfermagem psiquiátrica, não acredito muito, porque elas não parecem muito relevantes, senão seriam mais conhecidas".

"As pesquisas em enfermagem psiquiátrica têm pouca influência nos serviços. Elas quase não existem". 
"A gente sabe que tem muita pesquisa que não contribui em muita coisa. São pesquisas que não são construídas a partir das necessidades de saúde da população. São pesquisas predestinadas às prateleiras". "Esta é uma possibilidade muito remota, pois os enfermeiros não pesquisam nada e o que pesquisam não tem nenhum impacto, pois se tivesse, pelo menos ouviríamos falar alguma coisa".

"Não sei se existe alguma pesquisa de influência em enfermagem psiquiátrica”.

Das falas daqueles (09 ou 36\%) que acreditam que as pesquisas possam influenciar a prática nos serviços, ampliando o conhecimento dos enfermeiros, levando-os a uma conseqüente mudança de atitude, destacam-se algumas:

\section{"Pode influenciar muito na mudança de atitude para a assistência. Tem muita coisa nova por ai que a gente não sabe e que pode ajudar no dia-a-dia com o paciente". "Pode influenciar no serviço, pode mudar certas atitudes das pessoas com relação ao doente. Renova a dinâmica do tratamento tanto do enfermeiro como dos outros profissionais da equipe". \\ "Ela pode enriquecer meus conhecimentos e ajudar a melhorar meu trabalho".}

Pode-se constatar, na realidade estudada, que as pesquisas em enfermagem psiquiátrica parecem exercer pouca influência no exercício da prática profissional, pois sua aplicabilidade é, ainda, inexpressiva. Os enfermeiros da área psiquiátrica, na realidade investigada, ao serem absorvidos no mercado de trabalho, são englobados pelos direcionamentos das instituições empregadoras que, em geral, estão mais voltados para a produtividade do que, mesmo, para a qualidade da assistência prestada à clientela. Estes profissionais assumem o papel de administradores de conflitos, mantendo o elo entre a política estabelecida pelo serviço e os interesses imediatos da clientela. Esta postura, aliada à pouca experiência, dificulta, a esses sujeitos, questionar a validade desse comportamento e a conseqüente modificação da prática rotineira, alienante e defasada a que se submetem. Ademais, verificou-se que a maioria deles (24 ou 96\%) não tem assinatura de nenhum periódico da área o que, certamente, dificulta uma visão mais ampla e questionadora da sua prática, além de não estimular a busca para a descoberta do novo.

Vale destacar, também, que mais da metade dos enfermeiros, isto é, 14 (56\%) têm menos de cinco anos de serviço em psiquiatria, uma área específica que requer preparo especial. Os que possuem maior tempo de serviço, ou seja, 14 (56\%) não demonstraram interesse na realização de pesquisas face a acomodação às rotinas estabelecidas, falta de incentivo institucional e, sobretudo, pela descrença de que as pesquisas possam influenciar na melhoria da assistência; consideraram-nas irrelevantes e demonstraram a desesperança por já terem vivenciado muitos projetos que preconizavam mudanças para a prática psiquiátrica e nenhum deles chegou a ser efetivado, "continuando tudo no mesmo".

Foi identificado, ainda, nos pronunciamentos de $13(52 \%)$ dos enfermeiros, a falta de incentivo das instituições formadoras que, no ensino da disciplina 'metodologia da pesquisa' não os instrumentalizaram adequadamente, deixando de oferecer meios que pudessem, quando profissionais, garantir a busca do novo, empreendendo estudos a partir de sua prática. A este respeito, ALVES (1995), estudando a produção/ reprodução do conhecimento no trabalho da enfermagem, alerta para o fato de que a Escola, ao deixar de preparar agentes da enfermagem para a investigação, desqualifica o saber dos mesmos, enquanto alunos, além de torná-los vulneráveis quando da inserção dos mesmos no mercado de trabalho.

Considerando o processo de formação das Representações Sociais, verifica-se que a construção seletiva na enfermagem foi, ao longo da sua história, fruto da apropriação de determinados conhecimentos tidos como importantes para a profissão e, no âmbito da pesquisa, tem-se dado de forma insatisfatória, se consolidando como uma atividade que não tem sido devidamente valorizada e estimulada na área da assistência em enfermagem psiquiátrica. Ao nível da esquematização estruturante, verifica-se a existência de um relacionamento deficiente dos enfermeiros com a atividade científica que, ao nível da naturalização, chega, até mesmo, à negação da pesquisa como uma atividade indispensável para a construção de uma prática efetiva e competente.

\section{APRESENTANDO AS CONSIDERAÇÕES FINAIS}

Os resultados do presente estudo revelaram que os enfermeiros entrevistados, através de suas falas, expressaram seus valores, idéias, crenças e experiências vivenciadas, apresentando sua relação com o processo de produção, divulgação e utilização do conhecimento produzido na área de Enfermagem Psiquiátrica.

Verificou-se que a maior parte dos enfermeiros entrevistados não revelou uma concepção estruturada a respeito da pesquisa na área, por não se considerar familiarizada com o processo de investigação científica. 
Observou-se, também, que estes sujeitos não têm nenhuma expectativa em relação às pesquisas pela dificuldade de acesso às mesmas e, por não achá-las relevantes, não acreditam que possam modificar a prática da assistência na Enfermagem Psiquiátrica. Externaram, ainda, que as pesquisas não têm influencia no seu trabalho diário por não serem acessíveis, vez que não são devidamente divulgadas e, por isso mesmo, não têm seus resultados aplicados. No entanto, estes enfermeiros admitiram que a pesquisa é importante e necessária para a melhoria do desempenho profissional.

As concepções e expectativas aqui apresentadas se constituíram num conjunto lógico, sistemático e coerente de representações, de normas e regras de conduta que caracterizam o modo de pensar e ver a pesquisa em Enfermagem Psiquiátrica. Esta forma de ver e pensar a pesquisa é determinada, de forma complexa e conflituosa, pelo contexto profissional em que o enfermeiro está inserido, que, por sua vez, define suas expectativas.

As falas contendo as concepções e expectativas, aqui apresentadas, não se constituíram, portanto, num simples transmissor de informações ou de intenções de um indivíduo em informar um outro; ao contrário, elas se apresentaram cheias de significados resultantes da relação de sentidos estabelecidos pelos sujeitos num contexto social e histórico. Essas falas se constituíram no resultado das experiências elaboradas e tecidas no contexto onde foram vividas por cada profissional. São percepções e expectativas embasadas no concreto da vida desses sujeitos, constituindo-se, portanto, no produto do conhecimento socialmente elaborado e partilhado que, por sua vez, tem sua origem nas interações sociais do universo de cada enfermeiro. A realidade da relação dos enfermeiros com a pesquisa se dá, portanto, de uma forma socialmente construída.

Considerando-se os conceitos e fases constitutivas das RS, percebe-se que os enfermeiros, sujeitos desta investigação, necessitam construir seletivamente seu corpo de conhecimentos, de maneira que, ao nível da esquematização estruturante, estabeleçam uma estreita relação com as atividades de pesquisa e, assim possam naturalizar os conhecimentos produzidos, isto é, concretizar suas idéias em atividades práticas, tendo a investigação incorporada ao seu cotidiano e apreendida como uma atividade natural e necessária. Nessa perspectiva, eles deverão ancorar suas práticas nas atividades de pesquisa, buscando a apreensão do 'novo' que, associado aos conhecimentos já sedimentados, permitirá uma melhor compreensão da realidade onde os mesmos estão inseridos. Este conhecimento proveniente da incorporação social do 'novo', certamente, passa a ser utilizável, causando impacto efetivo na prática diária da enfermagem.

Para que isto seja concretizado, é necessária a concentração de esforços para a criação e estruturação de centros/grupos/núcleos de pesquisas que promovam integração de ações entre enfermeiros docentes e de serviços, bem como de estudantes, assegurando a produção do conhecimento voltada para as necessidades concretas dos serviços e da população, o que, certamente, facilitará sua divulgação e conseqüente implementação. A possibilidade desses profissionais trabalharem em parcerias, em todas as fases do processo de pesquisa, é condição fundamental para a incorporação dos seus resultados na prática assistencial.

Esse trabalho em parceria, por sua vez, implica no preparo de profissionais, fundamentado no conhecimento próprio da metodologia da pesquisa e na divulgação das experiências realizadas de forma a favorecer o processo cumulativo de produção/reprodução do conhecimento.

Depreende-se, ainda, a importância de uma política institucional que favoreça, estimule e incentive os enfermeiros para a busca da renovação de conhecimentos, instrumentalizando-os para produção do conhecimento direcionado para a prática, respondendo às reais necessidades da população e acompanhando os avanços tecnológicos da modernidade.

Recomenda-se, finalmente, para qualquer investigação que vise a aproximação da totalidade das questões aqui levantadas, que seja levada em consideração a realidade subjetiva dos agentes do processo de trabalho da Enfermagem Psiquiátrica e de suas condições materiais de existência.

\section{PSYCHIATRIC NURSING RESEARCH: CONCEPTIONS AND EXPECTATIONS OF NURSES IN PSYCHIATRIC INSTITUTIONS}

This research has as objects of study the conceptions and expectations of the clinical nurses in psychiatric institutions about the research developed in this area. It has the purpose to identify conceptions and expectations, enabling the identification of the process of dissemination and utilization of the research in the attention and administration of psychiatric nursing care. It was developed with nurses that work in psychiatric instituitions at Salvador, in March, 1997. 25 nurses who worked in the period were interviewed expressing their opinions concerning the theme in study, through semi-structured interview. Results were quantitatively analised, based on the theoretical-methodological design of the Social Representations. It was possible to conclude that the great part of the nurses interviewed mentioned that they did not have acess to research in this area, as well as 
demonstrated difficulty to find the relations and influence of these research in their service, however they admit its importance to personal and professional development, that certainly, reflects on nursing care.

KEY WORDS: research, psychiatric nursing research, psychiatric nursing

\section{INVESTIGACIÓN EN ENFERMERIA PSIQUIÁTRICA: CONCEPCIÓNES Y EXPECTATIVAS DE LOS ENFERMEROS QUE TRABAJAN EN INSTITUCIONES PSIQUIÁTRICAS}

Esta investigación tiene como objeto de estudio las concepciones y expectativas de los enfermeros actuantes en instituiciones psiquiátricas sobre las investigaciones desarolladas en esta area. Tiene como objetivo, identificar esas concepciones y expectativas, permitindo esbozar el proceso de divulgación y utilización de esas investigaciones en la atención y administración de la assistencia de enfermería psiquiátrica. Fue desarrollada con enfermeros que trabajam en instituciones psiquiátricas de la ciudad de Salvador, durante el mes de marzo de 1997. Fueron entrtevistados 25 enfermeros que se encontraban en servicio en el periodo previsto para la realización de la colecta de datos, quienes emitieron sus opiniones a través de guía de entrevista semi-estructurada. Los resultados fueron cualitativamente analizados y se apoyaron en los principios teórico-metodológicos de las Representaciones Sociales, permitindo concluir que la mayoría de los enfermeros entrevistados refirió no tener acceso a las investigaciones específicas del área, y demostró dificultad en establecer relación e influencia desas investigaciones en sus servicios aunque admitieron su importancia en le desarrollo personal y profesional, lo que repercutiría sobremanera en la asistencia prestada por los enfermeros.

TÉRMINOS CLAVES: investigación, investigación en enfermería psiquiátrica, enfermería psiquiátrica

\section{REFERÊNCIAS BIBLIOGRÁFICAS}

01. AlVES, D. de B. Produção Reprodução de conhecimentos no trabalho na enfermagem. Salvador, 1995. 244p. Tese (Doutorado) Faculdade de Educação, Universidade Federal da Bahia.

02. ARANTES, E.C. Pesquisa em enfermagem psiquiátrica. In: SEMINÁRIO NACIONAL DE PESQUISA EM ENFERMAGEM, 4. Anais. São Paulo, 1985.

03. BARNET, D.E. Do nurse read? Nurse manager and nursing research reports. Nurs. Times, v.77, n. 50, p. 213-14, Dec. 1981.

04. BLEGER, J. Temas de psicologia: entrevistas e grupos. São Paulo: Martins Fontes, 1993.

05. CASTRO, I. B et al. Dificuldade na incorporação do resultado de pesquisa na prática de enfermagem. In: SEMINÁRIO NACIONAL DE PESQUISA EM ENFERMAGEM, 4. Anais. São Paulo, 1985.
06. FERNANDES, J.D. A pesquisa na Escola de Enfermagem da Universidade Federal da Bahia. Revista Baiana de Enfermagem, Salvador, v. 1, n. 2, p. 46-69, dez.1985.

07. LOPES, C.M. Subsídio para uma reflexão acerca da aplicação de resultados de pesquisa pelo enfermeiro. Rev. Bras. Enfermagem, Brasília, v. 42, n. 1/4, p. 128-133, jan/dez. 1989.

08. MINAYO, M.C. de S. O desafio do conhecimento: pesquisa qualitativa em saúde. São Paulo: HUCITEC/ABRASCO, 1994.

09. MOSCOVICI, S. A representação Social da Psicanálise. Rio de janeiro: Zahar, 1978.

10. NÓBREGA, S.M. de. O que é representação Social? 1990 (mimeog.).

11. STEFANELLI, M.C. et al. Situação da pesquisa em enfermagem psiquiátrica no Brasil. Revista Escola Enfermagem USP, São Paulo, v. 21, n. 2, p. 183-95, ago. 1987.

12. VALA, J. Representações Sociais - para uma psicologia social do pensamento social. In: VALA, J.; MONTEIRO, M.B.(orgs.) Psicologia social. Lisboa: Fundação Calaiste Gulbenkiain, 1993.

13. WESTRUPP, M.H. et al. A pesquisa na enfermagem. Texto e Contexto Enfermagem, Florianópolis, v. 3, n. 1, p. 128-136, jan./jun. 1994. 